

\section{EXPEDIENTE}

Universidade do Estado do Rio de Janeiro - UERJ

Instituto de Estudos Sociais e Políticos - IESP

\section{CADERNOS DE ESTUDOS SOCIAIS E POLÍTICOS}

www.e-publicacoes.uerj.br/index.php/CESP

\section{COMITÊ EDITORIAL}

Giovana Esther Zucatto, IESP-UERJ

Helio Cannone, IESP-UERJ

Marcelo Borel, IESP-UERJ

Marcia Rangel Candido, IESP-UERJ

Marina Rute Pacheco, IESP-UERJ

Mariane Silva Reghim, IESP-UERJ

Paulo Joaquim Da Silva Rodrigues, IESP-UERJ

Raul Nunes de Oliveira, IESP-UERJ

\section{CAPA, LAYOUT E DIAGRAMAÇÃO}

Marcia Rangel Candido

Raul Nunes de Oliveira

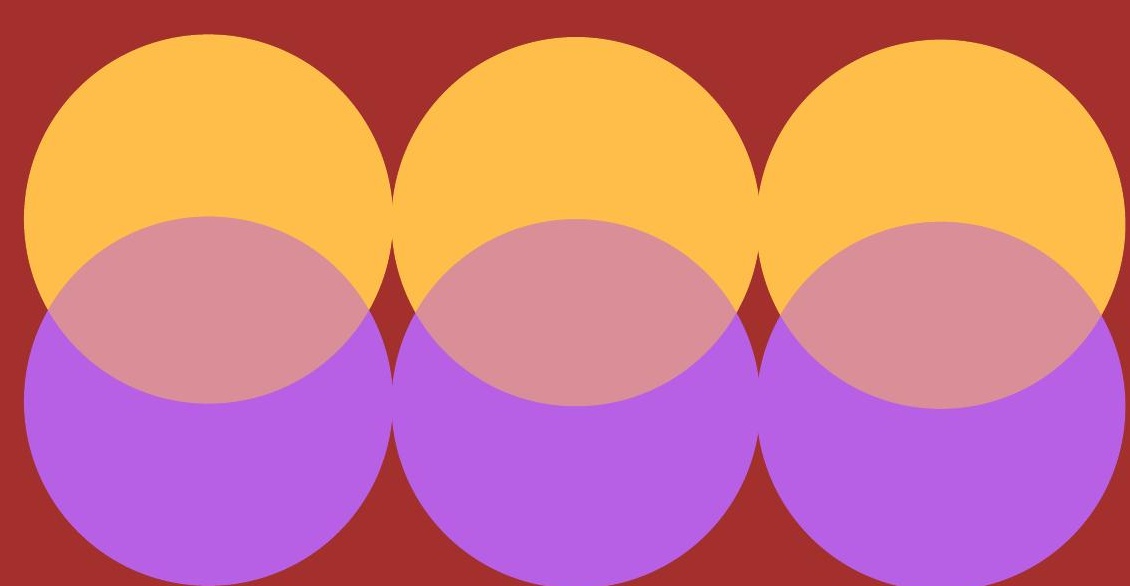


Apresentação

Mariane Silva Reghim e Marcelo Borel

Dossiê

As Expressões Do Racismo Institucional Nas Universidades Federais Do

Estado Do Rio De Janeiro: Mulheres Negras Trabalhadoras e Intelectuais

Cibele da Silva Henriques

Ressignificando As Raças: Os Deuses Pretos e Os Demônios Brancos No Discurso Nacionalista Preto Da Nação Do Islã nos Estados Unidos Da América

Rafael Filter Santos da Silva

Feminismo Negro e a Interseccionalidade de Gênero, Raça e Classe

Eunice Lea de Moraes Lucia Isabel Conceição da Silva

A Corporeidade e a Liberdade: Mulheres Negras e a Coragem De Ser

Joyce Gonçalves Restier da Costa Souza

\section{Artigos}

Os Governos Do PT e As Agências De Rating: Os Percalços De Treze Anos De Relação

Pedro Lange Netto Machado

Apropriação Cultural: Novas Configurações das Identidades na Era da Globalização

Bárbara Lopes Heleno e Rafaella Max Reinhardt

Resenha Crítica: O Segredo como Conceito Político: a propósito de Democracia e Segredo de Norberto Bobbio

Ronaldo Tadeu de Souza 
Cadernos de Estudos Sociais e Políticos, Rio de Janeiro, vol. 7, n 13, 2017

\title{
Os Governos Do PT e As Agências De Rating: Os Percalços De Treze Anos De Relação
}

The PT Governments and Rating Agencies: The Thirteen Year of Relationship

Pedro Lange Netto Machado ${ }^{1}$

\section{RESUMO}

O artigo analisa a relação entre os governos PT e as agências de rating. Uma vez que agendas de esquerda são vistas como de maior risco pelo mercado financeiro, argumenta-se de que as agências exerceram pressão, atuando como agentes disciplinadores em prol dos interesses do mercado financeiro, nos dois momentos em que vislumbraram o abandono dos preceitos neoliberais macroeconômicos por parte dos governos petistas. Essa hipótese é trabalhada pela análise dos movimentos do rating brasileiro, e de declarações das agências e do governo, que são confrontadas com a literatura especializada acerca da política econômica implementada pelos governos do PT. Este artigo contribui para uma maior compreensão acerca da viabilidade de governos de esquerda em meio às pressões exercidas pelo mundo financeiro.

PALAVRAS-CHAVE: Globalização financeira; Agências de rating; Esquerda; Partido dos Trabalhadores.

\begin{abstract}
This article analyzes the relationship between the PT governments and the credit rating agencies. Faced with a reality in which leftist agendas are seen as being riskier by the financial market, it is argued that the credit rating agencies exerted more pressure, acting as disciplining agents in the interests of the financial market, when they perceived the possibility of abandonment of the neoliberal macroeconomic precepts by the PT governments. This hypothesis is based on the analysis of Brazilian rating movements and statements from both agencies and the government, which are confronted with the specialized literature on the economic policy implemented by the PT governments. Once proven, this paper contributes to understand the viability of leftist governments amid the pressures exerted by the financial world.
\end{abstract}

KEY-WORDS: Financial globalization; Credit rating agencies; Left-wing; Worker's Party.

1 Bacharel em Relações Internacionais pela Universidade Federal Fluminense. Mestre em Relações Internacionais e Comércio Exterior pela Escuela Internacional de Negocios (ALITER). mestrando em Relações Internacionais com foco em economia política internacional pela Universidade Federal de Santa Catarina. Email: pedrolangenm@gmail.com 


\section{INTRODUÇÃO}

No mundo das finanças globalizadas, as agências de classificação de risco são um dos instrumentos pelos quais o mercado financeiro faz impor suas vontades aos Estados nacionais (YWATA, 2012). Dependentes das notas atribuídas por essas empresas para financiar seus deficits orçamentários, governos passam a ser pressionados a adotar políticas neoliberais - que se traduzem em austeridade econômica - para que possam estabilizar seus balanços de pagamentos. Essa realidade se coloca como um especial desafio aos governos de esquerda, sobretudo os de países emergentes, que se veem em meio ao conflito de interesses entre as demandas de seus eleitores e as exigências do sistema financeiro internacional (MOSLEY, 2003). Desse modo, a implementação de uma agenda de esquerda, essencialmente conflitiva com os interesses do mundo financeiro, pode ter

como consequência uma má avaliação por parte das agências de rating, o que, por sua vez, é capaz de gerar sérios problemas para a saúde econômica do país.

Um caso representativo desse dilema é o ocorrido no Brasil, ao longo dos governos do Partido dos Trabalhadores (PT), entre 2003 e 2016. Com uma agenda de governo historicamente avessa aos interesses do mercado financeiro, o PT teve que lidar com as pressões exercidas pelo sistema internacional de finanças - canalizadas pelas agências de rating -, e com as expectativas de um eleitorado que por mais de uma década se habituou a ouvir do partido um discurso conflitante com o do mundo das finanças. Não obstante, o que se percebe, ao longo dos treze anos de relação que se construiria, é que o esperado atrito só se concretizou em dois momentos, que marcaram o início e o final dos governos petistas.

Diante desse panorama, a proposta deste artigo é analisar a interação entre os governos petistas e as agências de classificação de risco, argumentando que os dois momentos de maior conflito se deram diante da ameaça de que o PT desconstruísse a política macroeconômica neoliberal implementada no governo FHC. Tratam-se, efetivamente, dos dois momentos em que se verificam rebaixamentos da nota atribuída pelas agências ao Brasil. Essa hipótese é trabalhada a partir da análise da movimentação do rating soberano brasileiro e de manifestações tanto das agências quanto de personalidades do governo. Para que seja operacionalizada, contudo, torna-se conveniente 
explorar, na próxima seção deste artigo, alguns elementos relevantes acerca do que se convenciona chamar de globalização financeira e dos desafios enfrentados pelos governos de esquerda neste contexto. Na seção seguinte são analisadas as principais características e controvérsias em torno das agências de classificação de risco. Dessa forma, pode-se proceder à análise da relação entre estes atores e os governos petistas, de modo a se confirmar o argumento proposto.

\section{GLOBALIZAÇÃO FINANCEIRA E GOVERNOS DE ESQUERDA}

Ao longo do último quarto do século $\mathrm{XX}$, o processo que se convenciona chamar de globalização financeira viria a acentuar as contradições inerentes ao capitalismo democrático (STREECK, 2012). Durante a década de 1970, o desmonte do regime de Bretton Woods deu lugar a uma nova realidade, na qual o poder dos Estados soberanos é sobrepujado, em muitos aspectos da governança estatal, pelo poder que os mercados passavam a usufruir (STRANGE, 1998). A configuração dessa realidade, por sua vez, ocorre a partir de novas regulamentações, oriundas e capitaneadas pelo governo dos Estados Unidos, em favor de mercados cada vez mais dependentes da

geração de riqueza na esfera financeira. É em meio a esse contexto que os movimentos de liberalização dos sistemas financeiros ganham impulso, de modo a permitir a interpenetração entre os mercados financeiros nacionais e internacionais que se fazia necessária ao estabelecimento de mercados de capitais globalizados. Neste âmbito, a desintermediação financeira viabilizou a disseminação do financiamento através da emissão de instrumentos de dívida, que se colocava como uma alternativa mais vantajosa à obtenção de empréstimos por vias bancárias, por exemplo. Nesse sentido, no caso de Estados soberanos, a emissão de títulos da dívida pública se constituiu como a principal forma de endividamento de países no contexto de globalização financeira (MOSLEY, 2003).

Tal realidade, contudo, trouxe consigo alguns inconvenientes para os governos nacionais. Isso porque o financiamento nos mercados de capitais inviabiliza uma negociação direta com seus credores, que são investidores diversos e dispersos no mundo financeiro (como investidores 
institucionais, que assumem a forma de fundos mútuos ou fundos de pensão, por exemplo). Desse modo, torna-se necessária a implementação de políticas que sinalizem o comprometimento do país com as regras da globalização financeira para garantir a confiança desses atores e, assim, atrair seus investimentos. Em contrapartida, a adoção de políticas que provoquem desconfiança acerca da capacidade de pagamento do Estado em questão pode ter como resultado uma fuga de capitais - e suas inerentes consequências para o balanço de pagamentos -, assim como uma maior dificuldade para a captação de recursos, o que se traduz em juros mais altos cobrados pelos credores (KAPLAN, 2011).

É com a finalidade de adequar os países à era da globalização e de evitar eventos como esse que os preceitos do Consenso de Washington passaram a ser disseminados pelas instituições da governança econômica global, sobretudo a partir da década de 1990. Nesse sentido, medidas como a liberalização financeira e comercial, disciplina fiscal, privatizações, e redução dos gastos públicos de modo a conter pressões inflacionárias, são apontadas por Williamson (1993) como necessárias à consecução de tal objetivo. No caso dos países emergentes da América Latina, como o Brasil, a adequação aos preceitos do Consenso de Washington ocorre paralelamente à implementação do Plano Brady, que viabilizou a conversão da dívida externa dos países em dívida pública, a partir da emissão de Brady bonds respaldados pelos Estados Unidos e pelo Fundo Monetário Internacional (FMI) - o que solucionaria a crise da dívida desses países e impulsionaria seus ingressos nos mercados de capitais como emissores de dívida (MOSLEY, 2003).

A necessidade de alinhamento ao receituário neoliberal do Consenso de Washington para garantir a confiança do mercado financeiro passaria, no entanto, a conflitar com a pauta tradicional de governos de esquerda - que tendem a adotar políticas expansionistas visando garantir a geração de empregos, ainda que em detrimento do controle da inflação (HIBBS, 1977). Em se tratando de um país emergente governado pela esquerda, tal realidade se torna ainda mais problemática, uma vez que suas economias são mais dependentes do ingresso de capital externo para financiar suas dívidas, ao passo em que seus governos são, nesse caso, vistos com maior desconfiança pelo mercado. Contudo, uma consequência disso foi que, ao final do século XX, a esquerda buscou se adequar ao contexto de mobilidade de capitais que se estabeleceu, adaptando suas políticas macroeconômicos às exigências do mundo financeiro (GARRETT, 1998; MOSLEY, 2003). Isso não significa, porém, que 
não seja vigiada com maior perícia pelos atores do mercado nem que, por vezes, sofra com discriminações político-partidárias (MOSLEY, 2003; CAMPELLO 2015), como será apresentado ao longo deste artigo.

\section{AS AGÊNCIAS DE CLASSIFICAÇÃO DE RISCO}

No contexto de globalização financeira, um dos mecanismos que mediam o relacionamento entre investidores e governos e por meio dos quais as finanças exercem seu poder sobre os Estados são as agências de classificação de risco - também conhecidas como agências de rating. A relevância dessas empresas privadas está estreitamente vinculada ao estabelecimento de mercados de capitais globalizados e desintermediados, onde a assimetria informacional existente entre investidores tomadores de empréstimos potencializou a demanda pelos seus serviços. Nesse contexto, as agências cumprem a função de informar ao mercado acerca do risco relativo de investimentos em dívida pública, avaliando a capacidade e a vontade desses Estados ${ }^{2}$ em honrar seus compromissos nas condições e prazos pactuados. Tal informação, por sua vez, assume a forma de um rating soberano, representado por um conceito elaborado a partir de uma série de variáveis qualitativas e quantitativas. A emissão do rating soberano passa, assim, a produzir fortes impactos na saúde financeira dos países avaliados, uma vez que dele dependem suas condições de acesso ao mercado de capitais ${ }^{3}$, onde investidores cobrarão juros correspondentes à nota recebida (YWATA, 2012).

Ao longo da década de 1990, o Brasil firmou contrato com as três principais agências Standard \& Poor's (S\&P), Moody's e Fitch Ratings ${ }^{4}$, que na prática monopolizam o segmento de rating soberano (TESOURO NACIONAL, 2018) $)^{5}$. O período em que isso ocorreu não é uma

2 Também podem ser objetos de avaliação dessas agências empresas e governos subnacionais. A análise proposta neste trabalho, contudo, restringe-se a Estados.

3 É com base nesse rating que investidores pautam suas decisões de investimentos - muitas delas, inclusive, condicionadas legalmente ao recebimento de uma determinada nota para que se concretize (SINCLAIR, 2005).

4 Neste artigo, todas as menções a "agências de classificação de risco" ou aos ratings delas provenientes se referem a essas três empresas.

5 A página na internet do Tesouro Nacional disponibiliza todos os movimentos do rating soberano brasileiro em perspectiva histórica, a partir dos quais se baseará a próxima seção deste artigo. 
coincidência, uma vez que nesse intervalo os governos do país aderiram aos preceitos do Consenso de Washington como via para alcançar o desenvolvimento. A abertura econômico-financeira potencializou, assim, o poder de vigilância dessas empresas que usam de sua prerrogativa avaliativa para pressionar o governo a adotar as políticas por elas consideradas adequadas - uma vez que suas manifestações não se limitam a emissão de um rating, assumindo também a forma discursiva, seja através de seus relatórios ou declarações de dirigentes na mídia. Esse modus operandi, por conseguinte, permite que as agências de rating atuem lançando mão até de chantagens e ameaças frente a governos mais dependentes de suas avaliações (YWATA, 2012).

Com efeito, não são poucas as críticas da literatura acerca da atuação desses atores, as quais identificam uma série de falhas tanto na atribuição das notas quanto no próprio processo de elaboração do rating. Sinclair (2005), por exemplo, observa que, conquanto se apresentem como técnicas e imparciais, as agências de rating são entidades eminentemente políticas, que desde a própria elaboração do rating incorporam em seus julgamentos uma visão de mundo particularmente voltada aos interesses dos credores. De fato, uma das principais funções dessas empresas seria a de um canal transmissor de políticas e normas neoliberais, traduzidas no Consenso de Washington, que visam à sincronização e à convergência institucional dos Estados - então reféns do financiamento nos mercados de capitais. No mesmo sentido, Kundu (2001) identifica o rating como instrumento de persuasão que faz com que governos sigam a agenda do mercado financeiro, pautada pela disciplina fiscal. Já Paudyn (2014), também em linha semelhante, destaca o caráter despolitizador do rating, que faz com que uma série de questões de política econômica sejam blindadas do debate político, uma vez que são apresentadas pelas agências como temas técnicos e científicos para o progresso de um determinado país. O resultado disso seria uma bifurcação artificial entre política e economia fomentada pelas agências de classificação de risco.

É à luz dessas percepções que algumas inconsistências na distribuição de notas que vêm sendo denunciadas pela literatura podem ser esclarecidas. Uma vez que as agências atuam como porta-vozes do Consenso de Washington, torna-se mais compreensível, por exemplo, que, primariamente, atribuam notas mais baixas a países governados pela esquerda, simplesmente pela ideologia político partidária de seus governantes (BARTA \& JOHNSTON, 2017; MOSLEY, 2003; VAALER, SHRAGE \& BLOCK, 2006). Isso porque, como observado por Barta e Johnston (2017), 
Cadernos de Estudos Sociais e Políticos, Rio de Janeiro, vol. 7, nº 13, 2017

a orientação ideológica de partidos políticos pode se constituir, para as agências, como um informativo acerca de potenciais políticas a serem implementadas, de modo a fazê-las agir preventivamente. Ao final e ao cabo, tais discriminações políticas e partidárias reforçam a ideia de que essas empresas atuam como guardiãs da disciplina fiscal, sobretudo em sua relação com países emergentes (HANUSCH \& VAALER, 2013). No caso brasileiro, ao longo dos governos do PT, alguns desses elementos se manifestaram mais explicitamente, como será melhor analisado a seguir.

\section{OS GOVERNOS PETISTAS E AS AGÊNCIAS DE RATING}

Diante do panorama apresentado, esta seção propõe uma narrativa dos movimentos do rating soberano do Brasil ao longo dos governos petistas, de modo que seja possível visualizar de que maneira alguns aspectos da atuação das agências de classificação de risco - apresentados na seção precedente - se materializaram na realidade brasileira. Conquanto não seja um objetivo analisar a política econômica adotada pelos governos do PT ou avaliar a conjuntura internacional na qual estes se inseriram, alguns elementos dessa natureza serão apresentados para que se possa melhor compreender os movimentos do rating brasileiro e suas consequências. Em seguida, a dinâmica das mudanças das notas recebidas pelo país é confrontada com análises e teorias que permitem melhor compreendê-la. Dessa maneira, busca-se operacionalizar o argumento de que as agências se constituíram em um instrumento disciplinador - em consonância com os preceitos neoliberais - dos governos petistas, de a modo a puni-los diante de qualquer ameaça de desvio desse padrão.

OS TREZE ANOS DE RELAÇÃO ENTRE O PT E AS AGÊNCIAS DE RATING

Ainda que o governo Lula só tenha se iniciado em 2003, a relação entre o PT e as agências de classificação de risco começa no ano anterior, em meio à disputa eleitoral. Diante de um discurso 
historicamente avesso aos interesses do mercado financeiro, no qual se defendia inclusive o calote da dívida externa (CAMPELLO, 2015), investidores já reagiam mal à medida que a vitória do candidato da esquerda se tornava mais provável (JENSEN; SCHMITH, 2005). Uma das expressões do pânico que se desenhava com a iminente vitória de Lula foi o rebaixamento do rating soberano brasileiro pelas três principais agências de classificação de risco, entre junho e agosto de 2002. Em comunicado noticiado pela Folha de S. Paulo (2002), a Fitch Ratings, por exemplo, declarou que o rebaixamento refletia "a piora nos fundamentos do crédito do Brasil conduzidos pelas persistentes incertezas sobre a continuidade da atual política econômica e a sustentabilidade da dívida como um resultado da transição política do Brasil”. É nesse contexto que o então futuro presidente Lula, para tentar conter as inquietações em torno de seu governo, buscou garantir, na Carta ao Povo Brasileiro (2002) que:

O PT e seus parceiros têm plena consciência de que a superação do atual modelo [...] não se fará num passe de mágica, de um dia para o outro. [...] Premissa dessa transição será naturalmente o respeito aos contratos e obrigações do país. [...] Vamos preservar o superávit primário o quanto for necessário para impedir que a dívida interna aumente e destrua a confiança na capacidade do governo de honrar seus compromissos (Carta ao Povo Brasileiro, 2002).

Poucos dias depois, foi a vez do assessor econômico de Lula, Guido Mantega, reafirmar em entrevista à BBC (2002) o compromisso do partido com seus credores. Para o futuro Ministro da Fazenda, declarar a moratória “(...) seria uma bobagem, uma atitude desnecessária. O Brasil tem condições de administrar sua dívida pública, tanto a interna quanto a externa. Estamos vivendo um momento difícil, mas é passageiro. Não há razão nenhuma para dar calote.” Na ocasião, Mantega destacou seu posicionamento favorável à independência do Banco Central, alinhando-se a um dos pilares do Consenso de Washington.

A desconfiança, contudo, não se esvaiu apenas com promessas, e o cenário em que Lula assumiu a presidência foi marcado por fuga de capitais, desvalorização do real e inflação ascendente (SANTOS, 2012). Diante desse panorama, e sob o constrangimento das agências - tanto em forma discursiva quanto em piora nas notas -, o novo governo, a partir de 2003, começou efetivamente a demonstrar seu comprometimento com as políticas de austeridade que já vinham sendo implementadas - por exemplo, com corte de gastos públicos e aumento dos juros, além da 
manutenção do tripé macroeconômico ${ }^{6}$ do governo $\mathrm{FHC}$-, e montando uma equipe econômica em sintonia com a agenda do mercado (SINGER, 2009). O rompimento com as propostas historicamente defendidas pelo PT, por conseguinte, tornava-se evidente, surpreendendo setores diversos do espectro político brasileiro, e alas do próprio partido ${ }^{7}$ (GOLDFRANK; WAMPLER, 2008). Em contrapartida, essas ações se refletiram nas sucessivas melhoras na avaliação do rating brasileiro pelas agências de classificação de risco. Em setembro de 2004, as três já haviam elevado a nota do país.

Paralelamente, a configuração de uma conjuntura internacional favorável - especialmente devido ao boom no preço das commodities - passou a conferir ao governo uma maior margem de manobra para a adoção de políticas microeconômicas mais identificadas com sua agenda original (CAMPELLO, 2015). Dessa forma, sob os auspícios da ortodoxia macroeconômica, o PT encontrou espaço para implementar políticas sociais e medidas de fomento ao mercado interno, o que ajudou a impulsionar o crescimento econômico no qual o país ingressava. Nesse contexto, nem mesmo a crise do "mensalão" foi o suficiente para abalar a confiança do mercado no presidente - então avaliado como pertencente à "esquerda responsável" (ibidem). Isso que permitiu que as eleições de 2006 transcorressem, para os investidores, de modo bem mais tranquilo do que a anterior. Com efeito, conforme noticiado pela Folha de S. Paulo (2005), em julho de 2005, a S\&P declarava que "a investigação das denúncias dentro do sistema democrático dá uma ideia da forte estrutura institucional do país".

No entanto, o que suscitava inquietações nas agências era a substituição, em 2006, de Palocci por Mantega no Ministério da Fazenda, que passou a gerar expectativas em torno de uma possível guinada à esquerda por parte do governo (FOLHA DE S. PAULO, 2006). Essas preocupações, não obstante, mostraram-se infundadas no decorrer do segundo mandato de Lula, que seguiu privilegiando a disciplina fiscal e a manutenção do tripé macroeconômico (SINGER, 2009). A partir de então, o sucesso das políticas redistributivas e de expansão do mercado interno, associado ao

6 Em 1999, o governo FHC, respaldado pelo FMI, estabeleceu como matriz macroeconômica um regime de câmbio flutuante, metas de inflação e metas de superávit primário que estabilizasse a relação da dívida pública com o PIB - dessa forma, estabelecia-se o tripé macroeconômico, em conformidade com a ortodoxia neoliberal vigente (BRESSERPEREIRA, 2012).

7 Tais divergências estão na origem da fundação do Partido Socialismo e Liberdade (PSOL) por membros do PT que não admitiram a conduta do governo. 
crescimento do PIB e ao registro de sucessivos superávits primários, instaurou um clima de otimismo com relação à obtenção do grau de investimento. De fato, o ano de 2007 foi marcado por novas elevações na nota do país, com as três agências o colocando a um ou dois conceitos abaixo do selo de bom pagador. Toda essa expectativa se refletiu na ida do próprio ministro Mantega à Nova Iorque, para fazer lobby nas agências por uma nota melhor - caso contrário, segundo o ministro, eram elas que corriam o risco de ficarem desmoralizadas (FOLHA DE S. PAULO, 2007).

O grau de investimento viria no ano seguinte, com a S\&P sendo a primeira a promover o rating brasileiro a esse patamar em 30 de abril de 2008. Um mês depois, foi a vez da Fitch Ratings atribuir ao país o selo de confiança. $\mathrm{Na}$ ocasião, a diretora sênior para ratings soberanos da agência, Shelly Shetty, elogiou a condição do país à Folha de S. Paulo (2008):

\footnotetext{
A impressionante melhora das finanças externas, em parte puxada pela alta do preço das commodities, mas também um resultado da boa gerência polícia juntamente com o status de credor líquido soberano, fez o Brasil ficar muito mais resistente aos choques financeiros globais e aumentou sua credibilidade em relação à sua política macroeconômica.
}

Já a Moody’s elevou a avaliação do país ao mesmo nível apenas no ano seguinte, já em meio as repercussões da crise econômica global desencadeada em outubro de 2008. Nesse sentido, em setembro de 2009, o Brasil já era considerado pela empresa um vencedor em meio à crise, o que se traduziu no discurso otimista do então presidente do Banco Central, Henrique Meirelles: "uma agência como essa, conservadora, considerar o país vencedor, isso é, de fato, um selo que confirma tudo aquilo que tem sido dito pelo presidente, no sentido de que o Brasil entrou forte, tomou as medidas adequadas, e saiu da crise mais rápido e mais forte do que muitos países" (FOLHA DE S. PAULO, 2009). O FMI, por sua vez, justificaria a mudança de patamar do rating brasileiro a partir da boa gestão macroeconômica do país, ressaltando a manutenção do tripé neoliberal por quase uma década: "Um aspecto positivo é que, na fase de expansão, a América Latina reduziu vulnerabilidades. Com quase uma década de gestão macroeconômica consistente, o Brasil é um ótimo exemplo" (O GLOBO, 2016).

Assim, com o cenário de estabilidade e confiança que se estabeleceu, as eleições de 2010 transcorreram também sem preocupações no mundo financeiro. $\mathrm{Na}$ realidade, como observado por Campello (2015), não havia grandes distinções entre os programas concorrentes do PT e do PSDB, 
uma vez que a candidata Dilma Rousseff reiterava o compromisso de seu governo com a disciplina fiscal e a política macroeconômica até então vigente. Nesse cenário, enquanto a candidata petista vencia o pleito sem dificuldades, a dupla Meirelles e Mantega já demandava às agências novos upgrades no rating brasileiro. Como noticiado pela Folha de S. Paulo (2010), em abril daquele ano o ministro Mantega, durante a CPI da dívida pública, declarou que "poderíamos ter ratings melhores" e disse conversar com as agências. Com efeito, o ano de 2011 seria marcado por novas elevações na nota do país por parte da S\&P e da Fitch Ratings, que destacou que o novo governo demonstrava "sinais de maior contenção dos gastos públicos, que junto às perspectivas de crescimento saudável devem permitir uma melhora da dívida pública" (FOLHA DE S. PAULO, 2011). O clima de confiança permaneceria também no ano seguinte, com a confirmação da nota do país pelas três empresas.

Entretanto, toda essa atmosfera positiva começou a se alterar a partir de 2013 - devendo-se aqui destacar a conjuntura internacional desfavorável que se estabelecera na esteira da crise econômica global. Na realidade, já no ano anterior o tripé macroeconômico começou a ser deixado de lado em prol da nova matriz econômica ${ }^{8}$, à qual Singer (2015) se referiria como "ensaio desenvolvimentista". Nesse novo contexto, em fevereiro, o presidente do Banco Central, Alexandre Tombini, já admitiu estar preocupado com a inflação ${ }^{9}$, ao passo que, gradativamente, a mudança na gestão da economia e o baixo crescimento do PIB começou a sabotar a confiança do mercado para com o governo petista (SINGER, 2015). Sintomaticamente, em junho, a agência S\&P alterou a perspectiva ${ }^{10}$ da nota brasileira para negativa.

No cenário adverso que começou a se configurar, a desconfiança dos investidores quanto ao rumo do país aumentou, e a "nova matriz econômica" do governo Dilma foi sendo inviabilizada pelo aumento dos juros que o governo se viu obrigado a implementar (ibidem). Em 2014, o rebaixamento do rating pela S\&P e a revisão da perspectiva para negativa pela Moody's prenunciavam as

8 Conforme o autor, trata-se de como este denominou a política econômica colocada em prática por Mantega - chamada pelo ministro de "nova matriz econômica" - ao longo do governo de Dilma Rousseff. Tal política, de caráter anticíclico, é analisada por Singer (2015) como sendo pautada por: i) redução dos juros; ii) uso intensivo do BNDES; iii) aposta na reindustrialização; iv) desonerações; v) plano para a infraestrutura; vi) reforma no setor elétrico; vi) desvalorização do real; viii) controle de capitais; e ix) proteção ao produto nacional.

9 Trata-se de uma declaração dada à colunista d'O Globo, Miriam Leitão, em fevereiro de 2013.

10 Segundo a S\&P (2017), uma perspectiva negativa significa que há, pelo menos, uma chance em três de rebaixamento da nota nos seis a nove meses seguintes. 
turbulências que cercariam as eleições de outubro e que se colocariam para o novo governo que assumiria. Como seria de se esperar, a piora nas avaliações pelas agências passou a ser usada politicamente em desfavor do governo, como deixa claro a declaração, já em março daquele ano, do futuro candidato à presidência Aécio Neves, do PSDB:

Infelizmente aconteceu o previsto e o país teve sua nota de crédito rebaixada pela Standard \& Poor's. A decisão coroa uma temporada de equívocos cometidos pelo governo da presidente Dilma Rousseff na área econômica, mas não só nela. $O$ histórico de manipulações contábeis, o descuido com a boa aplicação dos recursos públicos, a leniência com a inflação, a ineficácia na realização dos investimentos necessários para destravar o país, em contrapartida aos exorbitantes gastos correntes, explica, com sobras, a indesejada decisão (PSDB, 2014).

Já em outubro de 2014, a diretora sênior da Fitch Ratings, Shelly Shetty, alertava o próximo governo quanto aos maus rumos da economia ${ }^{11}$ :

O próximo governo herdará uma economia que enfrenta múltiplos desafios em termos de baixo crescimento, inflação elevada e performance fiscal em deterioração. Portanto, ajustes de política serão fundamentais para determinar a trajetória futura dos ratings soberanos do Brasil e de sua perspectiva

É nesse contexto que, em contraste com as duas disputas anteriores, a eleição de 2014 é definida por uma estreita margem de 4\% dos votos, favorável à candidata do P'T. Imediatamente após o resultado, era a Moody's que destacava que o desafio de Rousseff seria recuperar a confiança do mercado (FOLHA DE S. PAULO, 2014). Em sintonia com as solicitações das agências, o governo reeleito, contrariando as promessas de sua campanha, aderiu rigorosamente à disciplina do mercado financeiro, fazendo com que a política econômica voltasse a ser ditada pela ortodoxia neoliberal (PAULANI, 2017). Não obstante, as iniciativas do governo não renderam o resultado esperado, e o ano de 2015 foi marcado por novos rebaixamentos do rating do país. Em agosto, a Moody's promoveu o primeiro downgrade do ano, enquanto, no mês seguinte, a S\&P retirou o rating brasileiro da categoria grau de investimento. Já a Fitch, nos meses de outubro e dezembro, promoveu um duplo rebaixamento na avaliação brasileira, que também teve como consequência a perda do grau do

11 Conforme noticiado pela Folha de S. Paulo (2014), trata-se de um contexto em que a agência já demandava a execução de "reformas estruturais". 
investimento. Em meio ao caos político e econômico que se formava, Dilma Rousseff, já em maio de 2016, foi afastada do cargo de presidente em decorrência do início de seu processo de impeachmento que pôs fim, dessa maneira, à relação entre o PT e as agências de rating.

\section{DUAS AMEAÇAS DE ROMPIMENTO COM A ORTODOXIA NEOLIBERAL}

A narrativa apresentada deixa claro que a atuação das agências de classificação de risco, ao longo dos governos petistas, foi muito além da emissão de um rating informativo aos investidores no mercado financeiro. $\mathrm{Na}$ realidade, tanto as notas por elas atribuídas ao país quanto suas manifestações discursivas demonstram a preocupação em moldar e constranger as escolhas políticas do governo, sobretudo diante de sua orientação de esquerda na condução de uma economia emergente. Esse aspecto se mostra mais evidente no plano macroeconômico, com as agências se mostrando verdadeiras guardiãs do tripé neoliberal lançado pelo governo de FHC em 1999. O pânico que se desenhava em 2002, diante da iminente vitória de Lula nas eleições - que supostamente seria uma séria ameaça à manutenção dessa política macroeconômica - e refletido nos rebaixamentos do rating brasileiro, torna-se ilustrativo para o caso já apontado pela literatura acerca do preconceito dessas empresas para com governos de esquerda. Por sinal, foi o próprio governo FHC que atentou para as incongruências das agências nesse cenário, conforme noticiado pela Folha de S. Paulo, em outubro de 2002:

\footnotetext{
A própria agência [Fitch Ratings], em nota divulgada na manhã de hoje, reconhece sua incapacidade de formar um juízo a respeito da matéria. No entanto, age como se soubesse que o próximo governo não será capaz de lidar de forma adequada com a questão, embora elogie sinais emitidos pelo candidato que lidera as pesquisas. [...] Ao não fornecer qualquer razão técnica para sustentar a sua tese, a agência transforma sua decisão em um exercício de especulação sobre o curso futuro dos eventos, exercício que poderia ser aplicado a qualquer país, levando ao mesmo tipo de conclusões equivocadas.
}

Não obstante, conforme apontado na subseção anterior, o governo Lula se mostrou fortemente comprometido com a manutenção do tripé neoliberal, adquirindo a confiança das agências e fazendo com que o rating brasileiro fosse gradativamente sendo melhor avaliado. Isso se deu em meio a uma conjuntura internacional favorável, que permitiu ao governo conciliar políticas 
microeconômicas de esquerda - como o programa Bolsa Família - com a ortodoxia neoliberal no plano macroeconômico. Com o crescimento econômico associado à disciplina do mercado, o governo Lula, conforme observado por Ywata (2012, p. 227), adotou uma estratégia de não enfrentamento com agências, e de perseguição ao grau de investimento. Como analisado, este objetivo foi concretizado entre 2008 e 2009, em meio a elogios das agências e a um cenário de crise econômica global que marcaria uma reversão da conjuntura internacional favorável que até então vigorava.

A configuração desse novo contexto fez, contudo, com que o Brasil fosse vigiado ainda mais de perto pelo mercado financeiro (CAMPELLO, 2015), e consequentemente pelas agências de classificação de risco. Paralelamente, o governo de Dilma Rousseff promoveu, a partir de 2012, o desmonte do tripé macroeconômico neoliberal, com a implementação da nova matriz econômica, que estabeleceu um conflito aberto com os setores rentistas da sociedade (SINGER, 2015; VACCARI \& PEREZ, 2017). Esses eventos foram um marco na relação entre os governos do PT e as agências de classificação de risco, que passaram a sistematicamente rebaixar a nota de risco do país - o que culminou na perda do grau de investimento e no uso político deste evento contra o governo. Nesse contexto caótico ressurgiu a percepção de que era necessário recuperar o tripé macroeconômico (OREIRO, 2016) - resultando no retorno escancarado à submissão à disciplina da ortodoxia neoliberal, explicitada no primeiro ano do segundo mandato de Rousseff, mas que não foi suficiente para readquirir a confiança das agências.

Diante desse panorama, o que se percebe é que o medo manifestado pelas agências de classificação de risco em 2002, relacionado ao abandono do tripé macroeconômico neoliberal, só viria a ser respaldado pela realidade cerca de uma década depois. A consequência disso é que, apenas nesses dois momentos da relação com o governo PT, foi necessário às agências lançar mão de seu principal instrumento disciplinador para constranger o governo a retornar ao caminho da ortodoxia neoliberal - que, conforme observado por Paulani (2017), não foi, em nenhum momento dos governos petistas, completamente abandonado ${ }^{12}$. Em contrapartida, entre esses dois momentos, se

12 Conforme a autora: "tomados em seu conjunto, os anos petistas revelam, portanto, um caráter errático e enorme oscilação: fidelidade integral, de inicio, aos cânones da prescrição ortodoxa (anos Palocci), inspiração Desenvolvimentista na sequência (anos PAC), reação embaralhada de ortodoxia com heterodoxia, mas certamente menos Desenvolvimentista que a etapa anterior, no primeiro período de Dilma, e novamente um retorno forte à ortodoxia nos últimos 16 meses de governo petista (com Joaquim Levy assumindo o Ministério da Fazenda)." 
verificou uma vigilância constante apenas no plano discursivo, premiando com notas mais altas a responsabilidade fiscal de um neodesenvolvimentismo que, conforme Boito Jr. e Berringer (2013), nunca excedeu os limites do modelo econômico neoliberal que previamente se estabelecera no país.

\section{CONCLUSÃO}

O advento da globalização financeira reconfigurou o relacionamento entre governos nacionais e seus credores, uma vez que a obtenção de empréstimos passou a ocorrer majoritariamente via financiamento nos mercados financeiros. Diante da importância desfrutada pelas agências de classificação de risco neste âmbito, o recebimento de uma avaliação melhor ou pior passa a ser de grande impacto para o balanço de pagamentos de um país. No caso de uma economia emergente governada por um partido de esquerda, como foi o caso do Brasil ao longo dos governos do PT, o relacionamento com essas agências pode vir a se tornar problemático, tanto devido à importância do rating para um país emergente quanto à incompatibilidade a priori existente entre um governo de esquerda e os preceitos do Consenso de Washington, que norteiam a ação das agências. Diante disso, este artigo analisou como essa relação se mostrou mais conflituosa nos dois momentos em que as agências se viram frente à possibilidade real de abandono do tripé macroeconômico neoliberal pelos governos petistas - passando a atribuir ao país, nessas ocasiões, notas piores, que passaram a incidir negativamente sobre a economia do país.

Isso não significa, contudo, que as agências sempre ajam dessa maneira em seu relacionamento com governos de esquerda em países emergentes. Com efeito, as limitações metodológicas desta pesquisa permitem tirar conclusões nesse sentido apenas circunstancialmente, voltadas, neste caso, para o período analisado no caso brasileiro. Desse modo, pesquisas mais abrangentes, que contemplem um número maior de países com a mesma condição do Brasil, viabilizariam conclusões mais contundentes nesse sentido.

Este artigo contribui, por conseguinte, para o debate em torno da atividade das agências de rating, sobretudo em um contexto marcado por contestações acerca de suas atuações, que se 
tornaram constante alvo de críticas diante do papel negativo e controverso que tiveram na recente crise econômica global - e em outras anteriores (KRUCK, 2016). Ademais, um melhor entendimento acerca da maneira como operam permite, por conseguinte, vislumbrar as possibilidades de ação de governos de esquerda em meio a esse contexto e, consequentemente, de avanços em termos de governança democrática. Diante da constante mutação da forma como o embate entre capitalismo e democracia se apresenta (STREECK, 2016), as agências de classificação de risco despontam, ao que tudo indica, como parte desse cenário que cabe à academia desvendar.

Submetido para avaliação em 14 de abril de 2018

Aprovado para publicação em 09 de julho de 2018

\section{BIBLIOGRAFIA}

BARTA, Zsófia; JOHNSTON, Alison. (2017), Rating politics? Partisan discrimination in credit ratings in developed economies. Comparative Political Studies, pp. 1-34.

BBC. (2002), 'Lula deixou esquerdismo de lado', diz economista do PT. Acessado em 14/02/2018 e disponível em http://www.bbc.com/portuguese/economia/020628 donm1ss.shtml

BOITO JR., Armando; BERRINGER, Tatiana. (2013), Brasil: Classes Sociais, Neodesenvolvimentismo e Política Externa nos Governos Lula e Dilma. Revista de Sociologia e Política, v. $21, \mathrm{n}^{\circ} 47$, pp. $31-38$.

BRESSER-PEREIRA, Luiz Carlos. (2012), O governo Dilma frente ao "tripé macroeconômico" e à direita liberal e dependente. Novos Estudos, v. 95, pp. 5-14.

CAMPELLO, Daniela. (2015), The politics of market discipline in Latin America: globalization and democracy. Cambridge, Cambridge University Press.

FOLHA DE S. PAULO. (2002), Fitch rebaixa avaliação do Brasil e cita transição. Folha de S. Paulo, acessado em 30/02/2018 e disponível em http://www1.folha.uol.com.br/folha/dinheiro/ult91u57523.shtml 
. (2002) Decisão da Fitch é extemporânea e equivocada, diz BC e Fazenda. Folha de S. Paulo, Acessado em 12/02/2018 e disponível em http:/ /www1.folha.uol.com.br/folha/dinheiro/ult91u57539.shtml

. (2005), Agência de risco ecoam o discurso da blindagem. Folha de S. Paulo, acessado em 30/12/2017 e disponível em http://www1.folha.uol.com.br/folha/dinheiro/ult91u98145.shtml

- (2005), Agência de risco ecoam o discurso da blindagem. Folha de S. Paulo, acessado em 30/12/2017 e disponível em http://www1.folha.uol.com.br/folha/dinheiro/ult91u98145.shtml

. (2006) Agência de risco teme guinada à esquerda. Folha de S. Paulo, acessado em 03/02/2018 e disponível em http://www1.folha.uol.com.br/fsp/dinheiro/fi0504200616.htm

. (2007) Governo faz lobby em NY por nota melhor. Folha de S. Paulo, acessado em 29/12/2017 e disponível em http://www1.folha.uol.com.br/fsp/dinheiro/fi1504200709.htm

. (2008) Fitch promove nota do Brasil para investimento. Folha de S. Paulo, acessado em 24/02/2018 e disponível em http://www1.folha.uol.com.br/mercado/2008/05/402207-fitchpromove-nota-de-risco-do-brasil-para-grau-de-investimento.shtml

- (2009), Nota da Moody's é um selo que confirma força da economia, diz Meirelles. Folha de S. Paulo, acessado em 19/01/2018 e disponível em http://www1.folha.uol.com.br/mercado/2009/09/627653-nota-da-moodys-e-um-selo-queconfirma-forca-da-economia-diz-meirelles.shtml

- (2011) Agência de classificação de risco eleva nota do Brasil. Folha de S. Paulo, acessado em 11/02/2018 e disponível em http://www1.folha.uol.com.br/poder/2011/04/897964-agencia-declassificacao-de-risco-eleva-nota-do-brasil.shtml

. (2014) Ajustes após eleições serão inevitáveis, diz Fitch. Folha de S. Paulo, acessado em 18/01/2018 e disponível em http://www1.folha.uol.com.br/mercado/2014/10/1533405-ajustespos-eleicao-serao-fundamentais-para-rating-do-brasil-diz-fitch.shtml

- (2014) Desafio imediato de Dilma é recuperar a confiança do mercado, diz Moody's. Folha de S. Paulo, acessado em 10/02/2018 e disponível em http://www1.folha.uol.com.br/mercado/2014/10/1539776-desafio-imediato-de-dilma-e-recuperarconfianca-do-mercado-diz-moodys.shtml

GARRET'T, Geoffrey. (1998), Partisan Politics in the Global Economy. Cambridge, Cambridge University Press.

GOLDFRANK, Benjamin; WAMPLER, Brian. (2008), From petista way to Brazilian way: how the PT changes in the road. Revista Debates, v. 2, n 2, pp. 245-271. 
HANUSCH, Marek; VAALER, Paul M. (2013), Credit rating agencies and elections in emerging democracies: guardians of fiscal discipline? Economics Letters, v. 119, pp. 251-254.

HIBBS JR., Douglas A. (1977), Political Parties and Macroeconomic Policies. The American Political Science Review, v. 71, pp. 1467-1487.

JENSEN, Nathan M.; SMITH, Scott. (2005). Market responses to politics: the rise of Lula and the decline of Brazilian stock markets. Comparative Political Studies, v. 38, n¹0, pp. 1245-1270.

KAPLAN, Stephen B. (2011), Globalization and austerity politics in Latin America. Acessado em 13/02/2018 e disponível em http://econweb.umd.edu/ davis/eventpapers/kaplanglobalization.pdf

KRUCK, Andreas. (2016), Resilient blunderers: credit rating fiascos and rating agencies' institutionalized status as private authorities, Journal of European Public Policy. Acessado em 23/02/2018 e disponível em http://dx.doi.org/10.1080/13501763.2015.1127274

KUNDU, Amitabh. (2001), Politics and economics of credit rating. Economic and Political Weekly, v. 36, n. 4, p. 293-295.

LEITÃO, Miriam. (2013), Alta desconfortável. O Globo. Acessado em 20/01/2018 e disponível em https://blogs.oglobo.globo.com/miriam-leitao/post/alta-desconfortavel-485606.html

MATHIS, Jérôme; MCANDREWS, James; ROCHET, Jean-Charles. (2009), Rating the raters: are reputational concerns powerful enough to discipline rating agencies? Journal of Monetary Economics, $\mathrm{v}$. 56, p. 657-674.

MOSLEY, Layna. (2003), Global capital and national governments. Cambridge, Cambridge University Press.

O GLOBO. (2016). As reações em 2008 e agora à nota de crédito do Brasil. Acessado em 13/02/2018 e disponível em https://oglobo.globo.com/economia/as-reacoes-em-2008-agora-notade-credito-do-brasil-17451231

OREIRO, José Luiz; MARCONI, Nelson. (2016), O novo-desenvolvimentismo e seus críticos. Cadernos do Desenvolvimento, v. 11, n ${ }^{\circ} 19$, pp. 167-179.

PAULANI, Leda Maria. (2017), A experiência brasileira entre 2003 e 2014: neodesenvolvimentismo? Cadernos de Desenvolvimento, v. 12, no 20, pp. 135-155.

PAUDYN, Bartholomew. (2014), Credit ratings and sovereign debt: the political economy of creditworthiness through risk and uncertainty. Palgrave Macmillan. 
Cadernos de Estudos Sociais e Políticos, Rio de Janeiro, vol. 7, n 13, 2017

PSDB. (2002) Declaração de Aécio Neves sobre corte na nota de crédito do Brasil. PSDB, acessado em 16/01/2018 e disponível em http://www.psdb.org.br/sc/declaracao-de-aecio-neves-sobre-cortena-nota-de-credito-do-brasil/

RATINGS, S\&P Global. (2017), S\&P Global Ratings coloca ratings de longo prazo 'BB' e 'brAA-' do Brasil em CreditWatch negativo por aumento das incertezas políticas. Comunicado à imprensa em 22 de maio de 2017.

SANTOS, Fabiano. (2012). "The Lula Government and the Social Democratic Experience in Brazil", in R. Boschi e C. H. Santana (eds.), Development and Semi-periphery: Post-neoliberal trajectories in South America and Central Eastern Europe, London, New York, Delhi, Anthem Press, pp. 305-326.

SINCLAIR, Timothy J. (2005), The new masters of capital: american bond rating agencies and the politics of creditworthiness. Cornell, Cornell University Press.

SINGER, André. (2009), Raízes sociais e ideológicas do lulismo. Novos Estudos, v. 81, pp. 83-102. (2015), Cutucando onças com varas curtas: o ensaio desenvolvimentista no primeiro mandato de Dilma Rousseff (2011-2014). Novos Estudos, v. 102, pp. 39-67.

SILVA, Luis Inácio Lula da. (2002), Carta ao povo brasileiro. Acessado em 14/01/2018 e disponível em http://www.iisg.nl/collections/carta ao povo brasileiro.pdf

STRANGE, Susan. (1998) The retreat of the state. Cambridge University Press.

STREECK, Wolfgang. (2012), As crises do capitalismo democrático. Novos Estudos, v. 92, pp. 35-56.

TESOURO NACIONAL. (2018) Classificação de risco da República Soberana do Brasil. Tesouro Nacional. Acessado em 30/01/2018 e disponível em http://www.tesouro.gov.br/en/classificacao-de$\underline{\text { risco }}$

VAALER, Paul. M.; SCHRAGE, Burkhard; N., \& BLOCK, Steven A. (2006), Elections, opportunism, partisanship and sovereign ratings in developing countries. Review of Development Economics, v. 10, pp. 154-170.

VACCARI, Gabriel da Silva; PEREZ, Reginaldo Teixeira. (2017), A Doxa Política das Finanças: o discurso dos banqueiros diante da nova matriz econômica do governo Dilma Rousseff. Revista Eletrônica de Ciência Política, v. 8, n 3.

WILLIAMSON, John. (1993), Democracy and the Washington Consensus. World Development, v. 21, no 8 , pp. 1329-1336. 
YWATA, Ricardo K. (2012), Ordem Mundial e Agências de Rating: o Brasil e as agências na era global (1996-2010). São Paulo, Editora Senac. 